\title{
Dissatisfaction with own body makes patients with eating disorders more sensitive to pain
}

This article was published in the following Dove Press journal:

Journal of Pain Research

17 July 2017

Number of times this article has been viewed

\section{Anna Yamamotova' \\ Josef Bulant ${ }^{2}$ \\ Vaclav Bocek ${ }^{3}$ \\ Hana Papezova ${ }^{2}$}

'Department of Normal, Pathological and Clinical Physiology, Third Faculty of Medicine, ${ }^{2}$ Department of Psychiatry, First Faculty of Medicine, ${ }^{3}$ Department of Neurology, Third Faculty of Medicine, Charles University, Prague, Czech Republic
Correspondence: Anna Yamamotova Department of Normal, Pathological and Clinical Physiology, Third Faculty of Medicine, Charles University, Ke Karlovu 4, 12000 Prague 2, Czech Republic Tel +420224902717

Email yamamoto@lf3.cuni.cz
Abstract: Body image represents a multidimensional concept including body image evaluation and perception of body appearance. Disturbances of body image perception are considered to be one of the central aspects of anorexia nervosa and bulimia nervosa. There is growing evidence that body image distortion can be associated with changes in pain perception. The aim of our study was to examine the associations between body image perception, body dissatisfaction, and nociception in women with eating disorders and age-matched healthy control women. We measured body dissatisfaction and pain sensitivity in 61 patients with Diagnostic and Statistical Manual of Mental Disorders-Fourth Edition diagnoses of eating disorders (31 anorexia nervosa and 30 bulimia nervosa) and in 30 healthy women. Thermal pain threshold latencies were evaluated using an analgesia meter and body image perception and body dissatisfaction were assessed using Anamorphic Micro software (digital pictures of their own body distorted into larger-body and thinner-body images). Patients with eating disorders overestimated their body size in comparison with healthy controls, but the two groups did not differ in body dissatisfaction. In anorexia and bulimia patient groups, body dissatisfaction (calculated in pixels as desired size/true image size) correlated with pain threshold latencies $(r=0.55, p=0.001)$, while between body image perception (determined as estimation size/true image size) and pain threshold, no correlation was found. Thus, we demonstrated that in patients with eating disorders, pain perception is significantly associated with emotional contrary to sensory (visual) processing of one's own body image. The more the patients desired to be thin, the more pain-sensitive they were. Our findings based on some shared mechanisms of body dissatisfaction and pain perception support the significance of negative emotions specific for eating disorders and contribute to better understanding of the psychosomatic characteristics of this spectrum of illnesses.

Keywords: anorexia nervosa, bulimia nervosa, pain perception, body image perception, body dissatisfaction, Anamorphic Micro

\section{Introduction}

Body image is a multidimensional construct that represents body image evaluation that comprises perceptions, attitudes, and feelings about body size and shape, and related behaviors. ${ }^{1}$ The perceptual dimension, also called body perception, reflects an individual's subjective expectancy of their body image, and the attitudinal dimension, also called body satisfaction, reflects an individual's feelings about their body appearance. . $^{2,3}$

Previous research has reported both positive and negative aspects of body image as a psychologic construct. While a satisfactory body image has been linked to longterm mental health and to well-being, ${ }^{4,5}$ body image dissatisfaction has been associated with a variety of disturbances that affect psychosocial functioning and quality of life 
and lead to unhealthy weight control behaviors and suicidal ideation. ${ }^{6,7}$

Body image dissatisfaction among adolescents has been shown in those who desired to lose weight and also in those who desired to gain weight. ${ }^{8}$ Kostanski et al $^{9}$ suggested that body image dissatisfaction differs significantly depending upon gender and body mass. They found a significant increase in body dissatisfaction across body weights among females, reflecting a prevalent desire to be thinner. ${ }^{9}$ It was also emphasized that adolescent perceptions and not their actual weight were associated with emotional distress. ${ }^{10}$

It is relatively well established that the body image is vulnerable to damage of the central structures that affect motor skills (motor cortex, basal ganglia, and cerebellum); however, the effect of emotions and the role of the peripheral nervous system are much less clear. Central representation of the body can be significantly modified by peripheral factors. Patients with phantom pain after amputation or complex regional pain syndrome frequently describe altered perceptions of their bodies. ${ }^{11}$ Persons so affected perceive their nonexistent or painful limb as dimensionally altered and in an abnormal or bizarre position relative to their body, even to the point of describing different skin texture or temperature. ${ }^{12}$ Severe pain is not the only thing that can distort the size of the affected body part; it is also typical of anesthesia, with the numb area feeling as though it is of different size, for example, it may feel larger than normal. ${ }^{13}$ A similar distortion of body size can also be observed with pain. ${ }^{14}$

There is growing evidence to suggest that body image can be distorted in people with pain, keeping in mind that the disturbances of body image and pain perception represent central aspects in anorexia nervosa (AN). Several studies have confirmed decreased pain sensitivity in patients with eating disorders; however, it still remains unclear what physiologic and psychologic factors are associated with this altered sensitivity. ${ }^{15-17}$

The aim of our study was to analyze the association between body image perception (BIP), body dissatisfaction, and nociception in women with eating disorders, relative to age-matched healthy women (controls). We hypothesized that as with patients suffering from chronic pain, a more distorted (enlarged) whole body image would be related to higher pain sensitivity, that is, lower pain thresholds.

\section{Methods}

\section{Participants}

Sixty-one patients with eating disorders were recruited consecutively from the inpatients of Eating Disorders Unit at the
Psychiatric Clinic of the First Faculty of Medicine, Charles University, Prague. Thirty-one patients fulfilled the Diagnostic and Statistical Manual of Mental Disorders-Fourth Edition criteria for AN and 30 patients for bulimia nervosa (BN).

Patients with eating disorders not otherwise specified, psychosis, or current abuse of psychoactive substances were excluded. All patients were tested during the first week of hospitalization. The control group consisted of 30 healthy age-matched women who were recruited from the local community. The additional exclusion criteria for both groups were current analgesic medication, pregnancy, diabetes, or neurologic illness.

Forty of the 61 patients were taking psychoactive medication at the time of the study: selective serotonin reuptake inhibitor antidepressants (32), olanzapine (7), and sulpiride (3). Three patients had a concurrent diagnosis of an affective disorder, 3 had an anxiety disorder (1 posttraumatic stress disorder), 5 had a previous history of substance abuse (abstinent for at least 3 months), and 21 had a history of autoaggressive behavior. As in our previous study, we found no principal effect of medication or comorbidity; therefore, patients taking psychoactive medication were not excluded from the analyses. ${ }^{18}$

This study was carried out in accordance with the Declaration of Helsinki (Br Med J 1964; 2: 177-178, as revised in 2008). After the procedures were fully explained, each participant signed an informed consent. The research was approved by the ethics committee of the Third Faculty of Medicine, Charles University, Prague.

\section{Pain threshold measurement}

Pain threshold latencies for thermal stimuli were measured by the same method as in our previous studies. ${ }^{17,18}$ Briefly, the participants were asked to put their finger on the aperture of thermal analgesia meter (Model 33; IITC Life Science, Woodland Hills, CA, USA), which applies radiant heat at a constant intensity, and then withdraw their finger when they started to feel pain. The time from start of the radiant heat to finger withdrawal was used as a measure of thermal pain threshold latency. To prevent tissue damage, the maximum duration of heat exposure was set at $10 \mathrm{~s}$. The pain threshold was measured on the dorsal aspect of the index, middle, and ring fingers of the dominant hand (all participants were right-handed). An average of the three measurements was used in the analysis.

\section{Self-report questionnaires}

Body attitude test (BAT) is a measure of body image disturbance (20 items; 0-5 Likert scoring) with a three-factor 
structure. Its three subscales measure negative appreciation of one's own body size (BAT-1), lack of familiarity with one's own body (BAT-2), and general body dissatisfaction (BAT-3). ${ }^{19,20}$ For this study, we used the total score. The Czech translations of the BAT had been previously validated in samples of eating disorder patients and healthy controls. ${ }^{21}$

\section{Anamorphic Micro}

BIP and dissatisfaction with one's own body (DIS) were measured using Anamorphic Micro Software (Liverpool, UK). Anamorphic Micro is a computerized body image assessment program. It is a validated technique that enables to distort the picture by up to $100 \%$ and make the picture either wider or narrower. In our procedure, a digital photograph of the participant's whole body, standing against a plain white wall was used. The photograph was then downloaded into the Anamorphic program. Then, the resulting pictures were enlarged or narrowed using the computer software (Figure 1). Participants were asked to adjust each photograph according to the following instructions: first, the image of yourself that you see on the screen has been modified; please adjust it so that it matches what you really look like; second, adjust the modified image, if necessary, so that it corresponds to how you would like to look.

The participants were asked to perform two estimations (once with a starting image that was $100 \%$ wider and another time with an image that was 50\% narrower) to provide a counterbalancing effect, thus reducing any bias (Anamorphic User Guide, 2008). The average of the two values was used for analysis.

The results were presented as three images shown together: the true image size, the estimated size, and the desired image size of the volunteer (Figure 1). Anamorphic Micro then calculates the ratio of the estimated image and true image in pixels (BIP) and the ratio of desired image and true image in pixels (DIS). BIP scores $>100 \%$ indicate an overestimation of size, whereas DIS scores $<100 \%$ indicate a desire to be thinner. Similar to previous reports, the discrepancy between current body size (true size) and ideal body size (desired size) is a reliable and validated measure of body size dissatisfaction. Therefore, we used BIP and DIS scores for data analysis. ${ }^{22-24}$ Finally, each participant's weight and height were measured and the BAT questionnaires were completed.

\section{Statistical analysis}

Between-group differences were analyzed using analysis of variance. Where indicated, simple planned comparisons were used in the post hoc analyses. Associations between pain sensitivity and BIP and DIS were analyzed using the Pearson correlation. The total scores of BAT were also correlated with the individual scores obtained for BIP and DIS. Differences were considered significant if $p<0.05$.

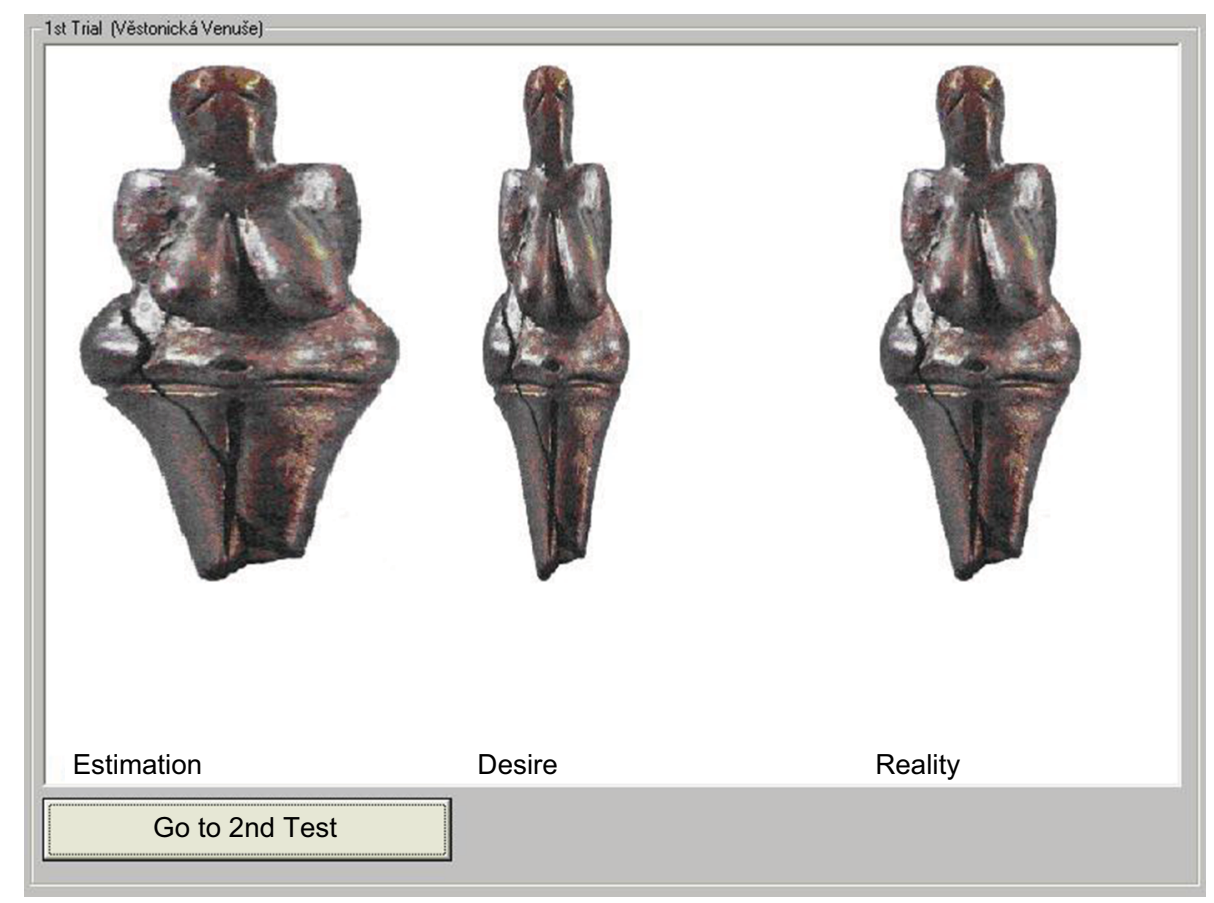

Figure I An Illustration from the Anamorphic Micro Program. (The Venus of Dolní Věstonice is a ceramic statuette of a nude female figure dated to 29,000-25,000 BCE, which was found at a Paleolithic site in the Moravian basin, south of Brno. This figurine is the oldest known ceramic article in the world.) 


\section{Results}

\section{Demographic and behavioral measures}

Results of analysis of variance are summarized in Table 1. Except for age and height, significant group differences were found in all observed variables.

\section{Thermal pain threshold latency}

Patients with $\mathrm{AN}$ and $\mathrm{BN}$ had higher pain thresholds than controls $(F(2,88)=5.349, p=0.0064$; Figure 2$)$. No significant differences were found between anorexia and bulimia patients.

\section{Anamorphic Micro and BAT}

Results from the BAT showed that patients with AN and BN were more dissatisfied with their bodies than control women $(F(2,88)=22.25, p<0.00001)$. No significant differences were found between anorexia and bulimia patients (Figure 3).

Both groups of patients with eating disorders overestimated their body size (123\% in bulimia and $130 \%$ in anorexia) to a greater extent than control women $(110 \%)$ (BIP: $F(2,88)=11.16, p=0.00005$; Figure 4).

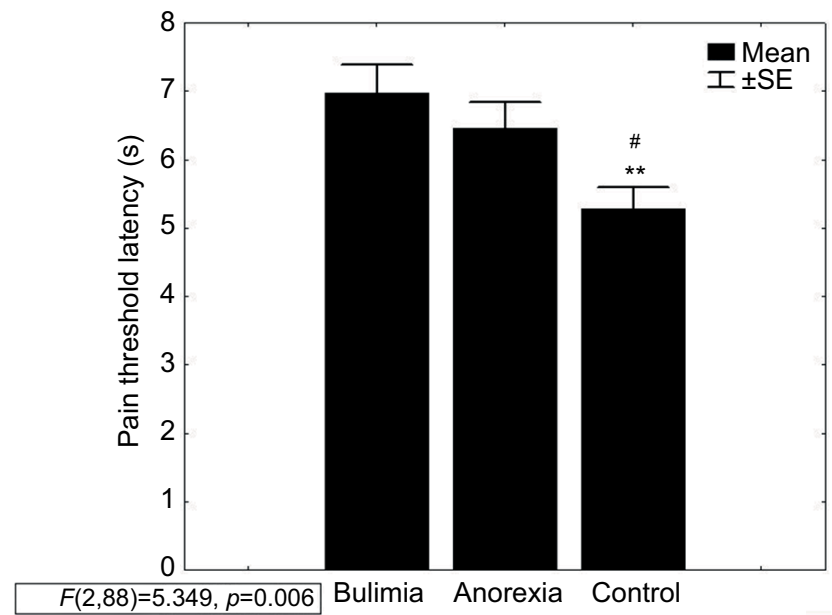

Figure 2 Pain threshold latency in $\mathrm{AN}$ and $\mathrm{BN}$ patients and controls. Note: ${ }^{* *} p<0.01 \mathrm{C}$ vs BN; \#p<0.05C vs AN.

Abbreviations: $\mathrm{AN}$, anorexia nervosa; $\mathrm{BN}$, bulimia nervosa; $\mathrm{C}$, controls; SE, standard error.
Patients with BN were more dissatisfied with their own bodies (their ideal figure should have been about $82 \%$ of their current figure) than AN and controls (97\% and $96 \%$, respectively) (DIS: $F(2,88)=6.85, p=0.0017$; Figure 5).

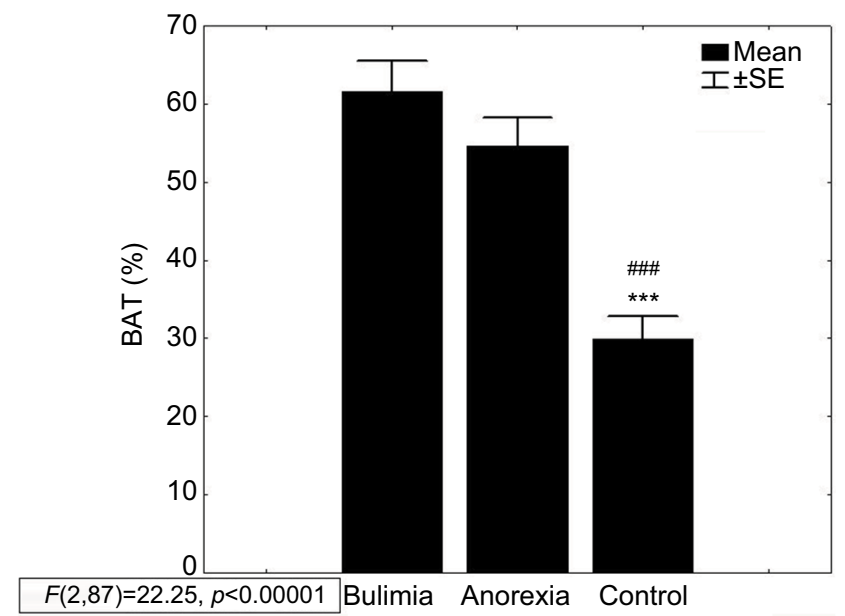

Figure 3 Body attitude test (BAT) in $\mathrm{AN}$ and $\mathrm{BN}$ patients and controls. Note: **** $p<0.001 \mathrm{C}$ vs BN; \#\#p<0.001 C vs AN.

Abbreviations: $\mathrm{AN}$, anorexia nervosa; $\mathrm{BN}$, bulimia nervosa; $\mathrm{C}$, controls; $\mathrm{SE}$, standard error.

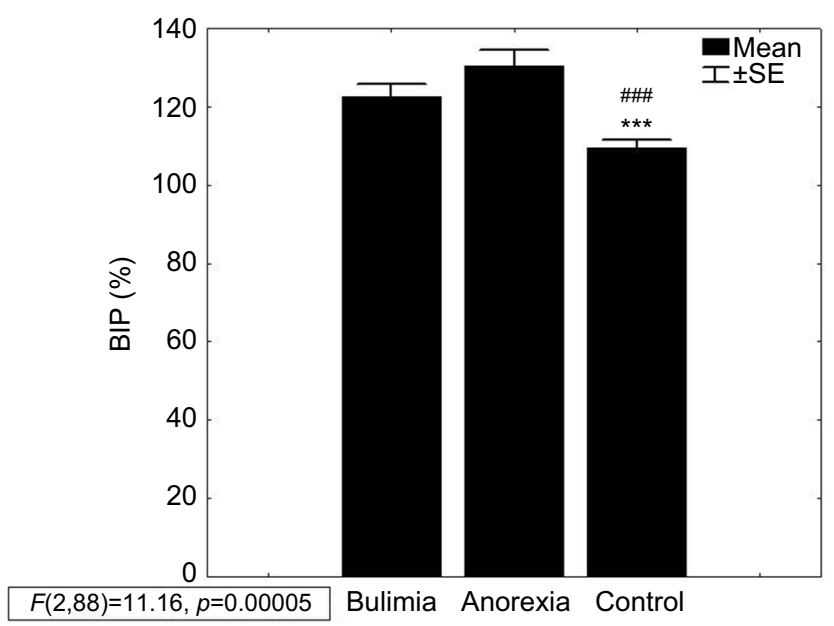

Figure 4 Body image perception (BIP) in $\mathrm{AN}$ and $\mathrm{BN}$ patients and controls. Note: ${ }^{* * *} p<0.001 \mathrm{C}$ vs $\mathrm{BN}$; \# $p<0.001 \mathrm{C}$ vs $A N$.

Abbreviations: AN, anorexia nervosa; BN, bulimia nervosa; C, controls; SE, standard error.

Table I Demographic and behavioral measures

\begin{tabular}{|c|c|c|c|c|c|}
\hline & \multirow{2}{*}{$\frac{\text { Anorexia, } \mathbf{n = 3} \text { I }}{\text { Mean } \pm \text { SD }}$} & \multirow{2}{*}{$\frac{\text { Bulimia, } n=30}{\text { Mean } \pm \text { SD }}$} & \multirow{2}{*}{$\frac{\text { Controls, } n=30}{\text { Mean } \pm S D}$} & \multicolumn{2}{|l|}{ ANOVA } \\
\hline & & & & $F(2,88)$ & $p$-value \\
\hline Age (years) & $24.3 \pm 5.4$ & $24.6 \pm 5.0$ & $23.0 \pm 3.3$ & 0.98 & 0.384 \\
\hline Weight (kg) & $45.3 \pm 6.6$ & $59.9 \pm 13.3$ & $65.8 \pm 8.7$ & 34.12 & 0.00000 \\
\hline Height (m) & $1.66 \pm 0.07$ & $1.67 \pm 0.07$ & $1.68 \pm 0.06$ & 0.88 & 0.418 \\
\hline BMI $\left(\mathrm{kg} / \mathrm{m}^{2}\right)$ & $16.6 \pm 2.0$ & $21.5 \pm 4.8$ & $23.3 \pm 3.3$ & 29.76 & 0.00000 \\
\hline BIP (\%) & $130.4 \pm 22.5$ & $122.7 \pm 16.6$ & $109.6 \pm 10.8$ & 11.16 & 0.00005 \\
\hline DIS (\%) & $96.8 \pm 24.7$ & $81.9 \pm 15.7$ & $96.4 \pm 9.8$ & 6.85 & 0.00172 \\
\hline BAT & $54.6 \pm 20.3$ & $61.6 \pm 21.3$ & $29.9 \pm 15.6$ & 22.25 & 0.00000 \\
\hline
\end{tabular}

Abbreviations: ANOVA, analysis of variance; BAT, body attitude test; BIP, body image perception; BMI, body mass index; DIS, dissatisfaction with one's own body. 
Both groups of patients showed greater variability in DIS than control subjects. In this respect, the control group was relatively homogeneous in comparison with patients with eating disorders. DIS and BIP in the control group were near the true image, which means that there was no substantial conflict between "what I see" and "what I desire to look like".

\section{Relationship between BIP, DIS, and BAT}

To confirm the validity of the Anamorphic Micro program results, we correlated scores from the BAT questionnaire with BIP and DIS. Results are shown in Table 2. We found that in both groups of patients as well as in controls, DIS negatively correlated with BAT (AN: $r=-0.56, p=0.001$; BN: $r=-0.56$, $p=0.002$; and controls: $r=-0.62, p=0.0003$ ). BIP was not related to BAT in patients with anorexia $(r=0.31, p=0.09)$, contrary to patients with bulimia and controls $(r=0.42, p=0.023$ and $r=0.39, p=0.031$, respectively). In Anamorphic Micro, the distortion of the whole body does not permit for manipulation of separate body parts. This could cause difficulties in assessing BIP among those patients who were dissatisfied with just specific body part that can be better described in the BAT.

BIP and DIS correlated only in eating disorder groups (AN: $r=-0.45, p=0.012$; BN: $r=-0.54, p=0.002$ ), but not in controls $(r=0.2, p=0.295)$. These observations may reflect

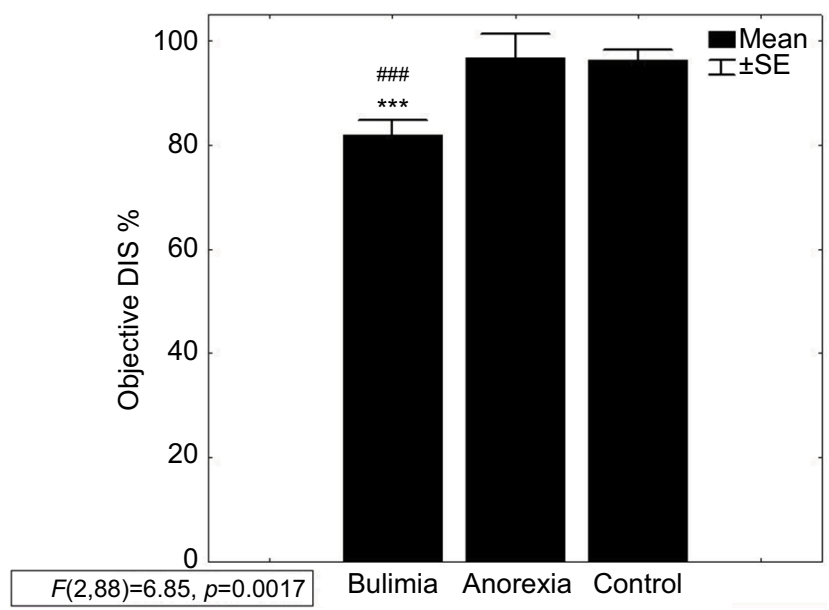

Figure 5 Dissatisfaction with one's own body (DIS) in AN and BN patients and controls.

Note: ${ }^{* * *} p<0.001 \mathrm{C}$ vs BN; \#\#p $<0.00$ I C vs AN.

Abbreviations: $\mathrm{AN}$, anorexia nervosa; $\mathrm{BN}$, bulimia nervosa; $\mathrm{C}$, controls; $\mathrm{SE}$, standard error. more realistic estimation of body size in healthy women, which is independent of satisfaction and, on the other hand, body size overestimation in patients predicts greater DIS.

\section{Relationship between pain threshold and BIP and DIS}

Perception of body size (BIP) was not correlated with the pain perception in any of the groups (Figure 6); however, in both groups of patients with eating disorders, pain perception significantly correlated with DIS (AN: $r=0.49, p=0.0047$; BN: $r=0.38, p=0.039)$ vs controls ( $r=-0.05, p=0.7726)$, as shown in Figure 7. Shorter latencies of withdrawal reactions (i.e., lower pain thresholds) were found in patients with stronger desire to be thinner (DIS $<100 \%$ ).

\section{Relationship between pain threshold modulation and disease characteristics in anorexia and BN}

Twenty-one patients (12 BN and $9 \mathrm{AN}$ ) with autoaggressive behavior did not differ from other patients in any of the monitored items (BIP: $123 \%$ vs $128 \%, t=1.02, p=0.31$; DIS: $85 \%$ vs $93 \%, t=1.38, p=0.17$; BAT: 63 vs $55, t=1.50, p=0.14$; and withdrawal latency: 6.9 vs $6.7 \mathrm{~s}, t=0.41, p=0.68$, respectively).

In addition, the analysis performed within diagnostic subgroups did not show any significant differences. Using Student's $t$-test, AN patients with autoaggressive behavior did not differ from AN patients without such behavior (BIP: $128 \%$ vs $131 \%, t=0.38, p=0.71$; DIS: $91 \%$ vs $99 \%, t=0.9$, $p=0.37$; BAT: 63 vs $51, t=1.6, p=0.12$; and withdrawal latency: 6.6 vs $6.4 \mathrm{~s}, t=0.28, p=0.78$, respectively), and also $\mathrm{BN}$ patients with autoaggressive behavior did not differ from BN patients without such behavior (BIP: $119 \%$ vs $125 \%$, $t=1.01, p=0.32$; DIS: $80 \%$ vs $83 \%, t=0.5, p=0.61$; BAT: 63 vs $60, t=0.37, p=0.71$; and withdrawal latency: 7.1 vs $6.8 \mathrm{~s}$, $t=0.28, p=0.78$, respectively). Due to an imbalance in the number of patients with and without autoaggressive behavior, we consider these results as preliminary.

\section{Discussion}

In patients with eating disorders, the distorted perception and negative affective evaluation of one's own body may be but one

Table 2 Correlation matrixes of the data obtained from BAT and the items BIP and DIS from Anamorphic Micro

\begin{tabular}{|c|c|c|c|c|c|c|}
\hline & \multicolumn{2}{|l|}{ Anorexia, $n=3$ I } & \multicolumn{2}{|l|}{ Bulimia, $n=30$} & \multicolumn{2}{|l|}{ Controls, $n=30$} \\
\hline & BIP & DIS & BIP & DIS & BIP & DIS \\
\hline DIS & $r=-0.45 ; p=0.012$ & & $r=-0.54 ; p=0.002$ & & $r=0.20 ; p=0.295$ & \\
\hline BAT & $r=0.31 ; p=0.09$ & $r=-0.56 ; p=0.001$ & $r=0.42 ; p=0.023$ & $r=-0.56 ; p=0.002$ & $r=0.39 ; p=0.031$ & $r=-0.62 ; p=0.000$ \\
\hline
\end{tabular}

Abbreviations: BAT, body attitude test; BIP, body image perception; DIS, dissatisfaction with one's own body. 


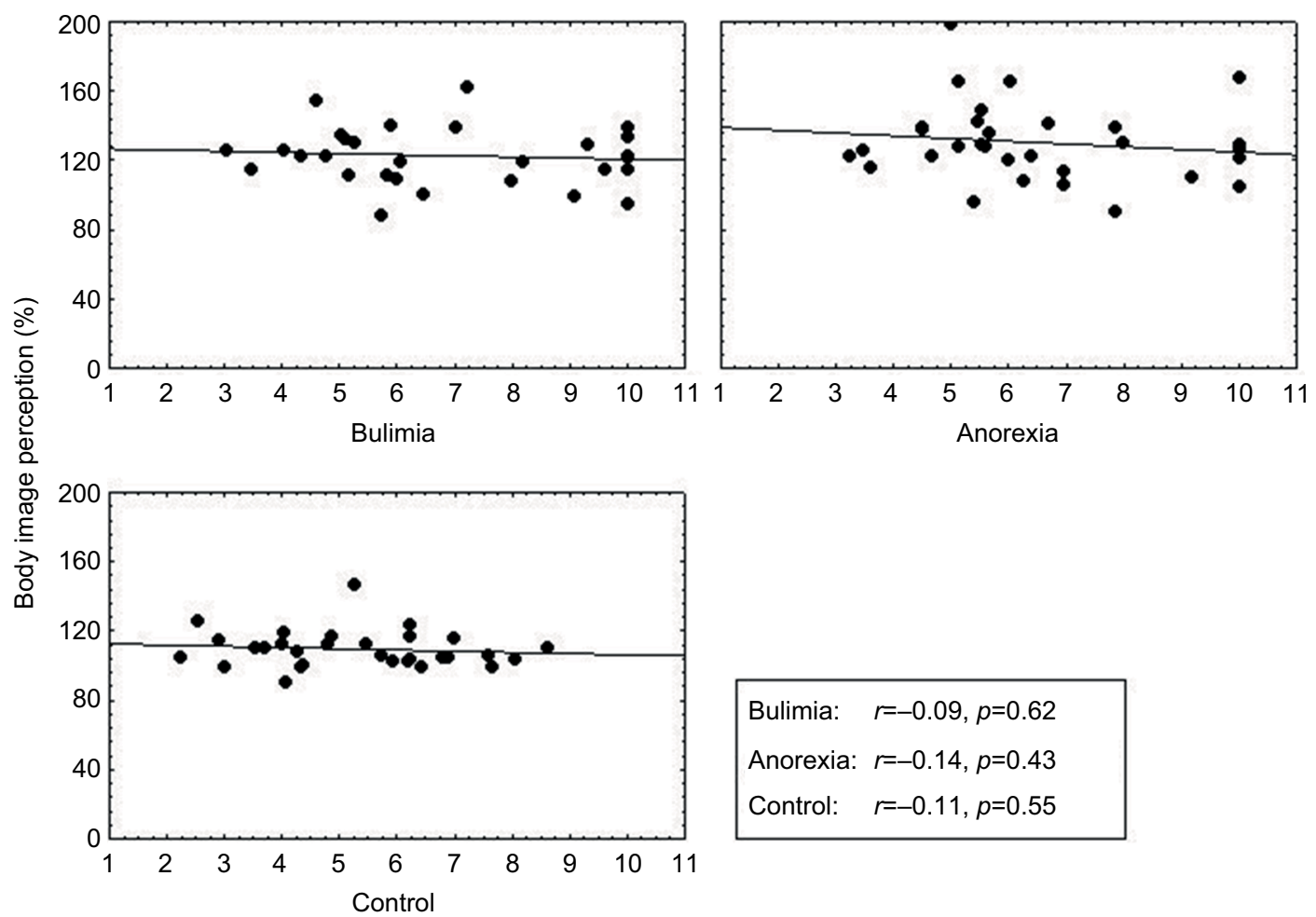

Pain threshold latency (s)

Figure 6 Correlation between pain threshold and body image perception.

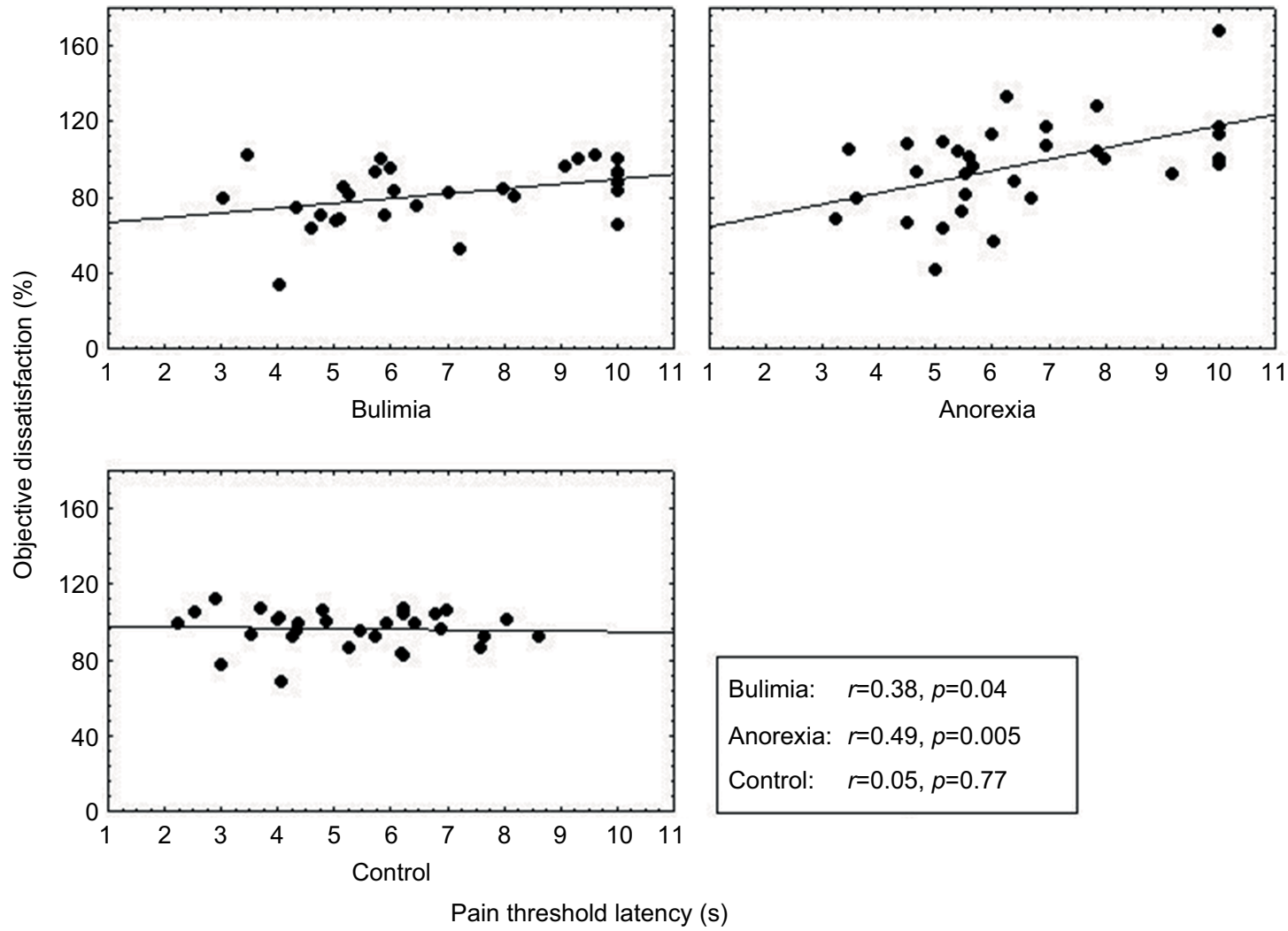

Figure 7 Correlation between pain threshold and body dissatisfaction. 
aspect of a more general disturbance in processing of bodily stimuli. Other manifestations of this hypothetic disturbance may be insensitivity to fatigue, hunger, and physical pain.

Originally, we expected similar relationship between perceived body size and subjective pain, as was described in patients suffering with pain. ${ }^{14,25}$ Therefore, we suspected that patients with the greatest tendency to overestimate their body size would have shorter withdrawal latencies (lower thermal threshold) relative to patients who estimated their body size more accurately. We were unable to confirm such a relationship, and therefore, our working hypothesis was not supported. However, we did find that the pain threshold in AN and BN groups was correlated with body dissatisfaction. Emotional representation of one's own body was more important than visual feedback from a resized image of one's own body. Surprisingly, this association was not found in healthy controls, although there is experimental evidence that manipulation with a magnified or distorted hand induces unpleasant emotions in healthy men. More negative emotions were felt toward the magnified image of the hand and in another study, pain-related negative body appearance caused increased pain sensitivity, particularly in subjects with lower pain thresholds. ${ }^{26,27}$

Similarity between pain and body perception consists of partially related perceptual, affective, and cognitive dimensions. Pain represents a negative emotion, and the amygdala appears to be a key brain structure in the overall pain matrix; it is thought to provide both positive and negative emotional values to sensory information, thus leading to adapted behavioral and affective responses and contributing to emotional memory. ${ }^{28,29}$ Seeger et al published the first study that showed right amygdala activation in AN patients after they were confronted with their own distorted body image. ${ }^{30}$ Similar results were observed in both types of anorexia - restricting and binge/purging - in response to their own fat image (artificially enlarged); however, this was not found in bulimia. ${ }^{31}$ A positive correlation between amygdala activation and modulation of extrastriate body area suggests that emotional signals are transmitted to the body-selective areas from the amygdala. ${ }^{32}$ Besides amygdala, increased activity has been observed in the dorsolateral prefrontal cortex, in $\mathrm{AN}$ patients vs healthy controls, in response to an oversized body picture; additionally, a significant correlation was found in AN patients between dorsolateral prefrontal cortex activation and eating disorder psychopathology according to Eating Disorder Questionnaire - shape concern. ${ }^{33}$ The dorsolateral prefrontal cortex is involved in regulating responses to emotional stimuli. When the recovered anorexic patients were exposed to painful heat stimuli, they showed less activation of posterior insula and more activation of dorsolateral prefrontal cortex (dlPFC). ${ }^{34} \mathrm{AN}$ is associated with a reduced capacity to accurately perceive interoceptive bodily signals which are central for basic homeostatic regulation. Using a heartbeat perception task, patients with AN displayed decreased interoceptive sensitivity. ${ }^{35}$ The insular and anterior cingulate cortices are also involved in the conscious processing of interoceptive stimuli. ${ }^{36}$

Disturbances in the processing of bodily stimuli may also be associated with the psychopathological process of dissociation. In our previous study, the relationship between body image disturbance and somatoform dissociation was explored using two self-report measures, which had been translated into the Czech language. ${ }^{21}$ The BAT and the Somatoform Dissociation Questionnaire ${ }^{37}$ were administered to 57 female patients with eating disorders (30 with AN; 27 with BN). Compared to a control group of 39 healthy women, patients with eating disorders scored significantly higher on both somatoform dissociation and pathologic body attitudes. Moreover, the two measures were highly positively associated both within the individual eating disorder groups as well as across the combined sample. The strongest association was found between somatoform dissociation and the lack of familiarity with one's own body (BAT-2 subscale). The results suggested that body image disturbance and dissociation in eating disorders were strongly related.

The BAT questionnaire represents a mixture of both perceptual and emotional attitudes toward one's body. In this study, we showed that the BAT was, in all groups, more related to body dissatisfaction than to BIP. More specifically, BAT and BIP were not correlated in patients with anorexia, which may reflect different processing of visual and verbal information concerning one's own body. Some results showed that AN patients have a disturbance in the metric properties of the mental representation of their body since they overestimate the size of tactile stimuli compared to controls. ${ }^{38}$ Moreover, in another study, it was shown that patients with AN judged horizontal tactile stimuli significantly larger than the same stimuli with vertical orientation. These findings imply that the human brain perception differs according to body representations and that the attitude to body size might influence the specific somatosensory process of tactile experience. ${ }^{39}$

This study has several limitations. Perception of pain and perception of the body were tested independently in different days; therefore, when we discuss an association between these two factors, we rather describe trait instead of state relationships. We did not assess how pain threshold is modulated in a given moment by DIS, but how general body dissatisfaction is related to individual pain sensitivity. Nevertheless, it does not mean that the observed relationships will be time invariant. 
Many studies have repeatedly found increased pain thresholds in patients with eating disorders, ${ }^{16,17,40-42}$ while others have found no changes in pain thresholds during shortterm treatment. ${ }^{43}$ However, there are no studies that have described the stability of this phenomenon from a long-term perspective. On the other hand, Probst et $\mathrm{al}^{44}$ assessed patient body experience before and after intensive therapy in 290 eating disorder patients using the BAT, the Eating Disorder Inventory, and the Eating Disorder Evaluation Scale, and they found that negative body experiences improved after therapy and these positive changes lasted for up to 1 year. The Eating Disorder Inventory scores and the Body Mass Index appeared to be the strongest predictors of the total BAT score at follow-up. ${ }^{44}$ Although body dissatisfaction can be quite persistent in eating disorders, intensive treatment can substantially improve the patient's body experience.

Contrary to this, very recent studies have demonstrated that body image can fluctuate in different situations and contexts, that is, body image is a dynamic phenomenon modified by many different stimuli such as eating food, one's own emotional signals, and other people's opinions and criticism about oneself and one's appearance. ${ }^{45,46}$ Further studies are needed to explore the long-term fluctuation of body and pain perception and their impact on course of the illness.

In this study, using anamorphic techniques, we found no relation between pain perception and the perception of one's own body size, that is, no association with the visual sensory component of body perception either between groups of patients with eating disorders or between patients and the women used as controls. In contrast to this finding, pain perception was significantly associated with the emotional component of body perception in both groups of patients. Greater DIS and, therefore, a greater desire to be thinner were associated with greater sensitivity to pain. Our results demonstrate that DIS reflects specific negative emotions in eating disorders that significantly influence eating behavior and pain perception. Our findings should significantly impact on our understanding of the psychosomatic characteristics associated with the clinical evaluation and treatment of patients with eating disorders. We also hope that our results will be included in the ongoing genetic research for new phenotypes linked to eating disorders.

\section{Conclusion}

In patients with eating disorders, pain perception is significantly associated with emotional, but not with sensory (visual) processing of their body image. Body dissatisfaction reflects negative emotions that share some mechanisms with the pain processing system. Specific body dissatisfaction may induce in those with eating disorders a greater sensitivity to bodily pain, in contrast with time-limited subjective relief of psychological pain associated with a narrowed focus on body appearance. This mechanism might explain the psychosomatic relationships, the long-term course of which needs further clarification.

The preliminary data of this paper were presented at a conference EFIC "Pain in Europe" in Florence, Italy, 2013. ${ }^{47}$

\section{Acknowledgment}

This work was supported by the grant IGA MZ CR NT/14094 and the projects PROGRES Q35 and PROGRES Q27.

\section{Author contributions}

AY and HP made substantial contributions to the conception of the paper and are responsible for the formulation of the hypothesis and interpretation of data. HP was responsible for patient selection; JB, VB, and AY were responsible for data collection and data analyses. All authors contributed toward data analysis, drafting and revising the paper and agree to be accountable for all aspects of the work.

\section{Disclosure}

The authors declare that the research was conducted in the absence of any commercial or financial relationships that could be construed as a potential conflict of interest.

\section{References}

1. Pruzinsky T, Cash TF. Understanding body images: historical and contemporary perspectives. In: Cash TF, Pruzinsky T, editors. Body Image: A Handbook of Theory, Research, and Clinical Practice. New York, NY: Guilford Press; 2002:3-12.

2. Ozmen D, Ozmen E, Ergin D, et al. The association of self-esteem, depression and body satisfaction with obesity among Turkish adolescents. BMC Public Health. 2007; 7:80.

3. Gardner RM. Methodological issues in assessment of the perceptual component of body image disturbance. Br J Psychol. 1996;87(Pt 2):327-337.

4. Mann MM, Hosman CM, Schaalma HP, de Vries NK. Self-esteem in a broad-spectrum approach for mental health promotion. Health Educ Res. 2004;19(4):357-372.

5. Kirkcaldy BD, Shephard RJ, Siefen RG. The relationship between physical activity and self-image and problem behaviour among adolescents. Soc Psychiatry Psychiatr Epidemiol. 2002;37(11):544-550.

6. Cash TF, Morrow JA, Hrabosky JI, Perry AA. How has body image changed? A cross-sectional investigation of college women and men from 1983 to 2001. J Consult Clin Psychol. 2004;72(6):1081-1089.

7. Kim DS, Cho Y, Cho SI, Lim IS. Body weight perception, unhealthy weight control behaviors, and suicidal ideation among Korean adolescents. J Sch Health. 2009;79(12):585-592.

8. Bearman SK, Presnell K, Martinez E, Stice E. The skinny on body dissatisfaction: a longitudinal study of adolescent girls and boys. $J$ Youth Adolesc. 2006;35(2):217-229.

9. Kostanski M, Fisher A, Gullone E. Current conceptualisation of body image dissatisfaction: have we got it wrong? J Child Psychol Psychiatry. 2004;45(7):1317-1325.

10. Al Sabbah H, Vereecken C, Abdeen Z, Coats E, Maes L. Associations of overweight and of weight dissatisfaction among Palestinian adolescents: findings from the national study of Palestinian school children (HBSC-WBG2004). J Hum Nutr Diet. 2009;22(1):40-49. 
11. Lotze M, Moseley GL. Role of distorted body image in pain. Curr Rheumatol Rep. 2007;9(6):488-496.

12. Lewis JS, Kersten P, McCabe CS, McPherson KM, Blake DR. Body perception disturbance: a contribution to pain in complex regional pain syndrome (CRPS). Pain. 2007;133(1-3):111-119.

13. Gandevia SC, Phegan CM. Perceptual distortions of the human body image produced by local anesthesia, pain and cutaneous stimulation. J Physiol. 1999;514(Pt 2):609-616.

14. Moseley GL, Parsons TJ, Spence C. Visual distortion of a limb modulates the pain and swelling evoked by movement. Curr Biol. (2008);18(22):R1047-R1048.

15. Gardner RM, Brown DL. Body size estimation in anorexia nervosa: a brief review of findings from 2003 through 2013. Psychiatry Res. 2014;219(3):407-410.

16. Lautenbacher S, Pauls AM, Strian F, Pirke KM, Krieg JC. Pain sensitivity in anorexia nervosa and bulimia nervosa. Biol Psychiatry. 1991;29(11):1073-1078

17. Papežová H, Yamamotová A, Uher R. Elevated pain threshold in eating disorders: physiological and psychological factors. J Psychiatric Res. 2005;39(4):431-438

18. Yamamotová A, Papežová H, Uher R. Modulation of thermal pain perception by stress and sweet taste in women with bulimia nervosa. Neuro Endocrionol Lett. 2009;30(2):237-244.

19. Probst M, Vandereycken W, Van Coppenolle H, Vanderlinden J. The body attitude test for patients with an eating disorder: psychometric characteristics of a new questionnaire. Eating Disord JTreat Prev. 1995;3(2):133-144.

20. Probst M, Van Coppenole H, Vandereycken W. Further experience with the body attitude test. Eat Weight Disord. 1997;2(2):100-104.

21. Uher R, Pavlova B, Papezova H, Probst M, Yamamotova A. Relation to one's own body and somatoform dissociation in eating disorders. Ceskoslovenska Psychologie. 2004;48(5):385-396.

22. Whitehouse AM, Freeman CL, Annandale A. Body size estimation in bulimia. Br J Psychiatry. 1986;149(1):98-103.

23. Letosa-Porta A, Ferrer-García M, Gutiérrez-Maldonado J. A program for assessing body image disturbance using adjustable partial image distortion. Behav Res Methods. 2005;37(4):638-643.

24. Docteur A, Urdapilleta I, Defrance C, Raison J. Body perception and satisfaction in obese, severely obese, and normal weight female patients Obesity (Silver Spring). 2009;18(7):1464-1465

25. Diers M, Zieglgänsberger W, Trojan J, Drevensek AM, Erhardt-Raum G, Flor H. Site-specific visual feedback reduces pain perception. Pain. 2013;154(6):890-896.

26. Osumi M, Imai R, Ueta K, Nakano H, Nobusako S, Morioka S. Factors associated with the modulation of pain by visual distortion of body size. Front Hum Neurosci. 2014;8:137. eCollection 2014a.

27. Osumi M, Imai R, Ueta K, Nobusako S, Morioka S. Negative body image associated with changes in the visual body appearance increases pain perception. PLoS One. 2014;9(9). eCollection 2014b.

28. Simons LE, Moulton EA, Linnman C, Carpino E, Becerra L, Borsook D. The human amygdala and pain: evidence from neuroimaging. Hum Brain Mapp. 2014;35(2):527-538.

29. Veinante P, Yalcin I, Barrot M. The amygdala between sensation and affect: a role in pain. J Mol Psychiatry. 2013;1(1):9.

30. Seeger G, Braus DF, Ruf M, Goldberger U, Schmidt MH. Body image distortion reveals amygdala activation in patients with anorexia nervosa - a functional magnetic resonance imaging study. Neurosci Lett. 2002;326(1):25-28.

\section{Journal of Pain Research}

\section{Publish your work in this journal}

The Journal of Pain Research is an international, peer reviewed, open access, online journal that welcomes laboratory and clinical findings in the fields of pain research and the prevention and management of pain. Original research, reviews, symposium reports, hypothesis formation and commentaries are all considered for publication.
31. Miyake Y, Okamoto Y, Onoda K, et al. Brain activation during the perception of distorted body images in eating disorders. Psychiatry Res. 2010;181(3):183-192.

32. Peelen MV, Atkinson AP, Andersson F, Vuilleumier P. Emotional modulation of body-selective visual areas. Soc Cogn Affect Neurosci. 2007;2(4):274-283.

33. Castellini G, Polito C, Bolognesi E, et al. Looking at my body. Similarities and differences between anorexia nervosa patients and controls in body image visual processing. Eur Psychiatry. 2013;28(7): $427-435$.

34. Strigo IA, Matthews SC, Simmons AN, et al. Altered insula activation during pain anticipation in individuals recovered from anorexia nervosa: evidence of interoceptive dysregulation. Int J Eat Disord. 2013;46(1): 23-33.

35. Pollatos O, Kurz AL, Albrecht J, et al. Reduced perception of bodily signals in anorexia nervosa. Eat Behav. 2008;9(4):381-388.

36. Schulz SM. Neural correlates of heart-focused interoception: a functional magnetic resonance imaging meta-analysis. Phil Trans $R$ Soc Lond B Biol Sci. 2016;371(1708):20160018.

37. Nijenhuis ER, Spinhoven P, Van Dyck R, Van der Hart O, Vanderlinden J. The development and the psychometric characteristics of the Somatoform Dissociation Questionnaire (SDQ-20). J Nerv Ment Dis. 1996;184(11):688-694.

38. Keizer A, Smeets MA, Dijkerman HC, van Elburg A, Postma A. Aberrant somatosensory perception in anorexia nervosa. Psychiatry Res. 2012;200(2-3):530-537.

39. Spitoni GF, Serino A, Cotugno A, Mancini F, Antonucci G, Pizzamiglio $\mathrm{L}$. The two dimensions of the body representation in women suffering from anorexia nervosa. Psychiatry Res. 2015;230(2) 181-188.

40. Faris PL, Raymond NC, de Zwaan M, Howard LA, Eckert ED, Mitchell JE. Nociceptive, but not tactile thresholds are elevated in bulimia nervosa. Biol Psychiatry. 1992;32(5):462-466.

41. Krieg JC, Roscher S, Strian F, Pirke KM, Lautenbacher S. Pain sensitivity in recovered anorexics, restrained and unrestrained eaters. J Psychosom Res. 1993;37(6):595-602.

42. de Zwaan M, Biener D, Schneider Ch, Stacher G. Relationship between thresholds to thermally and to mechanically induced pain in patients with eating disorders and healthy subjects. Pain. 1996;67(2-3): 511-512.

43. Lennkh C, de Zwaan M, Biener D, Stacher G. Does pain sensitivity change over time in patients with eating disorders? Biol Psychiatry. 1997;42(1 Suppl 1):103S.

44. Probst M, Vandereycken W, Van Coppenolle H, Pieters G. Body experience in eating disorders before and after treatment: a follow-up study. Eur Psychiatry. 1999;14(6):333-340.

45. Rudiger JA, Cash TF, Roehrig M, Thompson JK. Day-to-day bodyimage states: prospective predictors of intra-individual level and variability. Body Image. 2007;4(1):1-9.

46. Espeset EM, Gulliksen KS, Nordbø RH, Skårderud F, Holte A. Fluctuations of body images in anorexia nervosa: patients' perception of contextual triggers. Clin Psychol Psychother. 2011;19(6):518-530.

47. Yamamotova A, Papezova H. Visual body perception and nociception. Are they related in women with eating disorders?. Presented at: Pain In Europe VIII: 8th Congress of the European Federation of IASP Chapters (EFIC); October 9-12, 2013; Florence, Italy.

\section{Dovepress}

The manuscript management system is completely online and includes a very quick and fair peer-review system, which is all easy to use. Visit http://www.dovepress.com/testimonials.php to read real quotes from published authors. 